\title{
De Golpe à Abundância: alterações semânticas em expressões designativas do ato de bater
}

\author{
Blow to Abundance: Semantic Changes in Designatives EXPRESSiOnS \\ OF ACT TO BEAT
}

\section{Nathália Luiz de FREITAS*}

Resumo: Com base em elementos da Semântica Diacrônica e da Semântica Cognitiva, este artigo visa a analisar fatores linguístico-cognitivos envolvidos nas alterações semânticas ocorrentes em expressões designativas do ato de bater, tais como uma paulada, uma porrada, uma cacetada, uma porretada, uma pancada e uma bordoada, seguidas da preposição de, originando expressões que indicam quantidade e intensidade. A partir de uma perspectiva semasiológica (SILVA, 2005), o fenômeno em análise foi investigado em ocorrências identificadas no corpus constituído de expressões averiguadas e identificadas em portal eletrônico, de maneira que os procedimentos e as técnicas empregados têm características predominantemente qualitativas, havendo quantificação apenas no que se refere à frequência absoluta e conforme tipificação das expressões, isto é, à frequência relativa. Nossas análises indicam que a predicação por transferência - especialmente do sufixo -ada, enquanto processo sintático-semântico, e a figuratividade - notadamente o traço de intensidade presente nos substantivos que formam as expressões - como processo semântico-cognitivo são fatores identificados responsáveis pelas alterações de sentido nas expressões em foco.

Palavras-chave: Predicação. Figuratividade. Alterações semânticas.

* Doutoranda em Linguística pela Universidade Estadual de Campinas - UNICAMP. Mestra em Letras: Estudos da Linguagem pela Universidade Federal de Ouro Preto UFOP. Docente do Instituto Federal de Educação, Ciência e Tecnologia do Sul de Minas Gerais - IFSULDEMINAS -, campus Poços de Caldas. Contato: nathalia.freitas@ifsuldeminas.edu.br. 
Abstract: Based on elements of Diachronic Semantic and Cognitive Semantics, this article aims to analyze linguistic and cognitive factors involved in occurring semantic changes in designative expressions of the act of to beat, such as a uma paulada, uma porrada, uma cacetada, uma porretada, uma pancada e uma bordoada, followed by the preposition de, creating expressions that indicate quantity and intensity. From a semasiological perspective (SILVA, 2005), the phenomenon in question was investigated in events identified in the corpus of ascertained expressions and identified in electronic portal, so that the procedures and techniques used have predominantly qualitative characteristics, with quantification only as regards the absolute frequency and according to classification of the expressions, i.e., the relative frequency. Our analyzes indicate that the predication by transfer - especially -ADA suffix, while syntactic-semantic processing, and figurativity - notably the intensity of this trait in nouns that form the expressions - as semantic-cognitive process are identified factors responsible for changes meaning in expressions in focus. Keywords: Predication. Figurativity. Semantic changes.

\section{Introdução}

As línguas variam e mudam, fenômenos estes tributários dos usos que fazemos delas. Essa concepção parece ser, em alguma medida, consensual entre as tendências linguísticas contemporâneas, havendo divergências, entretanto, com relação ao foco e à ênfase conferidas pelas diferentes perspectivas a tais fenômenos. Especialmente no que se refere à mudança linguística, o ponto de vista basilar dos diferentes tipos de Funcionalismos ${ }^{1}$, isto é, o pressuposto de que a linguagem consiste em uma ferramenta cuja forma é adaptada às funções que exerce (PEZATTI, 2011), tem caráter central, já que, conforme sugere Martelotta (2011), o fato de as línguas mudarem figura como condição para o seu funcionamento. A mudança

${ }^{1}$ Em razão do escopo do presente trabalho, não serão tratadas aqui as diferentes posições das abordagens funcionalistas, mas é importante deixar claro não haver uniformidade entre elas. 
é parte constitutiva da natureza dinâmica das línguas e da função que elas desempenham.

Posto isso, assumir que a constituição linguística é emergente da linguagem em uso no contexto social significa defender não que a língua e suas mudanças se organizam aleatoriamente, mas que existe certa propensão à unidirecionalidade, conforme a qual, com o tempo, os elementos tendem a desenvolver valores mais subjetivos, os quais se tornam internamente menos composicionais (MARTELOTTA, 2011). Partimos desse posicionamento para analisar o fenômeno ora investigado, a saber, as alterações semânticas ocorrentes em expressões designativas do ato de bater, tais como uma paulada, uma porrada, uma cacetada, uma porretada, uma pancada e uma bordoada, seguidas da preposição de, originando expressões que indicam quantidade e intensidade.

Concebidas como expressões formulaicas, ou seja, expressões cujo significado está relacionado à noção de fórmula, através da qual os usos da linguagem ancoram-se em um padrão pré-estabelecido, definido e transmitido socialmente (ALENCAR, 2004; CAZELATO, 2006), as referidas expressões designativas do ato de bater, que, no contexto em análise, indicam quantidade e intensidade, representam uma manifestação da predicação. Entendida como uma operação de transferência de traços semânticos que se movimentam pela sentença e pelo texto, a predicação pode ser de natureza não composicional (CASTILHO, 1994), uma vez que a significação pode não estar nos sentidos dos itens relacionados, mas na predicação que gerou um significado novo, havendo a transferência do "conjunto de um 'lugar' léxicosemântico para outro” (CASTILHO, 1994, p. 83).

Nessa perspectiva, considerando que a compreensão dos sentidos veiculados pelo uso das expressões em foco depende não só da decodificação de cada um dos termos que as compõem, mas, também, exige o reconhecimento do seu valor idiomático, enquanto expressões formulaicas da língua portuguesa, especificamente da variante brasileira, hipotetizamos, nesta investigação, que a mudança semântica ocorrente é ocasionada por um fenômeno de transferência de traços semânticos, gerado pela predicação de natureza não composicional. Somado a isso, acreditamos que a figuratividade possui papel preponderante no fenômeno em questão, já que os traços semânticos de intensidade e força, presentes nos substantivos que constituem as expressões em análise, são reconfigurados no contexto dos idiomatismos 
criados e, juntamente aos outros elementos linguísticos, passam a atuar como quantificadores/intensificadores dos nomes que seguem essas expressões formulaicas.

O desenvolvimento de um estudo com esse objeto e nessa vertente justifica-se em razão de: i) não haver investigações que abordam o fenômeno de alterações semânticas ocorrentes nas referidas expressões designativas do ato de bater, gerando expressões que indicam quantidade e intensidade; ii) serem em abundância as ocorrências dessas expressões formulaicas; e iii) consistirem essa temática e essa abordagem em um expediente de especial relevância teórica e empírica para diferentes perspectivas semânticas, entre as quais faz-se importante ressaltar a Semântica Cognitiva e a Semântica Diacrônica, além de abordagens funcionalistas, de modo geral.

Partindo de uma abordagem semasiológica, fundamentada em categorias teóricas e analíticas pertencentes tanto à Semântica Cognitiva quanto à Semântica Diacrônica, assim como a partir de dados e análises ainda preliminares, buscaremos trazer elementos e discussões passíveis de corroborarem a hipótese ora defendida.

\section{Semântica e Predicação}

Se, no interior da Linguística, o ponto de vista cria o objeto, conforme assente Saussure (1974), o mesmo podemos afirmar para as investigações linguísticas que se ocupam dos sentidos expressos nas línguas naturais. Dessa forma, a depender do fenômeno enfocado, temos diferentes tipos de Semântica. Segundo propõe Castilho (2014), é possível, ainda que com dificuldades, delimitar campos de estudos semânticos de acordo com seus objetos. São eles:

(i) Semântica léxica, que trata dos sentidos das palavras, (ii) Semântica gramatical, que trata dos significados das construções, (iii) Semântica discursiva ou pragmática, que trata das significações geradas no intervalo que medeia entre os locutores e os signos linguísticos, (iv) Semântica cognitiva, que trata da criação dos sentidos. Acrescento algumas observações ainda muito preliminares sobre a (v) Semântica diacrônica, que trata da mudança dos sentidos (CASTILHO, 2014, p. 5). 
Tendo em vista ser a significação linguística um processo complexo, que envolve interlocutores, interação, língua, cognição, referenciação, entre outros fatores, em espaços e tempos histórico, cultural e socialmente estabelecidos, podemos afirmar que essa divisão é muito mais programática que factível. Assim, o presente trabalho se serve tanto de elementos da Semântica Cognitiva quanto de elementos da Semântica Diacrônica, tratando, pois, da criação de sentidos e da mudança de sentidos, sendo aquela necessária a esta.

Para o que pretendemos neste estudo, são necessários, no que se refere à Semântica Cognitiva, apontamentos sobre a lexicalização. De acordo com Castilho (2003), o léxico consiste em um conjunto de categorias cognitivas prévias à enunciação, baseados nas quais construímos os traços semânticos inerentes. São concebidas como categorias cognitivas: VISÃO, OBJETO, ESPAÇO, TEMPO, MOVIMENTO, EVENTO etc.; e como subcategorias: por exemplo, de VISÃO: (i) FUNDO / FIGURA, (ii) PERSPECTIVA etc.; de ESPAÇO: (i) VERTICALIDADE / HORIZONTALIDADE / TRANSVERSALIDADE, (ii) DISTÂNCIA / PROXIMIDADE, (iii) CONTINENTE / CONTEÚDO etc. Conforme o estudioso, os traços semânticos são constituídos a partir de tais categorias, nas quais, para OBJETO, temos, entre outros, os traços de contável $\sim$ não contável/, para ESPAÇO os de dentro $\sim$ fora etc. ${ }^{2}$

Nesse prisma, ao combinarmos categorias e traços de diferentes formas, obtemos os itens lexicais prototípicos, que terão suas realizações como um nome, um adjetivo, um advérbio, um artigo, uma preposição ou uma conjunção, o que corresponde assumir que, para cada um desses itens, existe certo arranjo de traços. A lexicalização consiste, desse modo, em um processo de criação de itens, por meio de seleção de propriedades cognitivas e de traços semânticos derivados sendo o léxico um conjunto de traços semântico-cognitivos (CASTILHO, 2003).

Seguindo esse raciocínio, entendemos que os nomes têm um sentido prototípico, pois “perfilam 'coisas' ou regiões num determinado domínio",

2 A formatação da representação das categorias de análise está em conformidade a Castilho (2003). 
de forma que “'os objetos físicos' são o protótipo dos nomes” (SILVA; BATORÉO, 2010, p. 235). Esse sentido prototípico é conferido pelas categorias e subcategorias cognitivas, que se desdobram por diversos processos em traços semânticos derivados. Em termos de categorias cognitivas, os sentidos prototípicos dos nomes correspondem à base OBJETO e às derivadas a CONCRETO E ABSTRATO, com relação a categorias semânticas em quantidade e qualidade e no que tange a traços e papeis semânticos em / contável/ / não contável/ etc. - para quantidade /causa/, /modo/, /posse/, /matéria/, /instrumento/, /condição/, / finalidade/, /meio/, /beneficiário/ etc. - para qualidade. Conforme Castilho (2003), há um processo derivativo que vai das categorias cognitivas de base até os traços e papéis semânticos.

Sob um ponto de vista cognitivo, a Semântica pode ser concebida como um campo de estudos que entende a criação dos significados a partir de estratégias cognitivas, entre as quais estão o emolduramento da cena, a hierarquização de seus participantes, a organização do campo visual, a movimentação real ou fictícia dos participantes, sua reconstrução através da metáfora e da metonímia etc., processos dos quais resultam as categorias semânticas de dêixis, referenciação, foricidade, conexidadade e predicação (CASTILHO, 2003). Para o que interessa à presente investigação, serão tratados aspectos relativos à predicação.

No que respeita à Semântica Diacrônica, importa-nos ressaltar que, sendo a disciplina que se ocupa dos processos de mudança de sentido, tem ela fundamental relevância nesta investigação. A mudança semântica é inerente à língua, de maneira que os estudos em diacronia figuram como arcabouço necessário ao entendimento de como e porque as alterações de sentido ocorrem. Desde Bréal (1911), cunhador do termo semântica, há considerações contundentes sobre as mudanças de significado das palavras, haja vista suas discussões sobre restrição do sentido, alargamento do sentido, metáfora, "espessamento" do sentido e polissemia.

Ullmann (1964) distingue os fatores que favorecem as alterações semânticas das causas que as geram. Entre os fatores elencados, estão o modo descontínuo como uma língua é transmitida de uma geração para outra, a imprecisão do significado e a perda de motivação. A polissemia pode introduzir na língua um elemento de flexibilidade, já que uma palavra 
pode assumir um significado novo, perdendo ou não o significado inicial. É ainda possível que as alterações semânticas ocorram em contextos ambíguos. Conforme o autor, o fator mais importante que favorece a mudança semântica é a estrutura do vocabulário, já que este é "uma estrutura instável em que as palavras individuais podem adquirir e perder significados" (ULLMANN, 1964, p. 390).

Quanto às causas da mudança semântica relacionadas por Ullmann (1964), elas são de caráter linguístico, histórico, social e psicológico. Também a influência estrangeira e a necessidade da criação de um nome podem contribuir para as alterações de significado. Na concepção do estudioso, independentemente das causas responsáveis pela mudança semântica, é imprescindível que haja uma associação entre o significado novo e o antigo, associação esta que pode ser subdividida em semelhança e contiguidade, sendo que, no eixo da primeira, está a metáfora, cuja figuratividade é constituinte basilar.

Uma categoria teórico-metodológica que pode ser tratada no âmbito das duas Semânticas aqui invocadas é a predicação, a qual, segundo Castilho (1994), pode ser definida como a relação entre um predicador e seus sujeitos. Conforme o linguista, ao citar a concepção aristotélica, a própria designação é um processo de predicação e, desse modo, cada item lexical pleno de significado consiste em um predicador, o que leva à postulação de que a predicação por designação produz o sentido, oriundo da relação entre o item e seu referente. Trata-se, pois, do entendimento da predicação como incidência de um item sobre o outro, processo este que gera significados não contidos no sentido dos itens lexicais envolvidos e que é tributário da relação entre um item-predicador e um item-sujeito.

Considerando, juntamente a Castilho (2014), que a identificação do sentido das palavras envolve os conceitos de intensão - conjunto dos traços semânticos inerentes do vocábulo - e de extensão - conjunto de indivíduos denotados por um vocábulo, podemos identificar na predicação três mecanismos:

(i) a transferência afetou a intensão da classe-escopo: ocorreu uma predicação por qualificação [...]; (ii) a transferência afetou a extensão da classe-escopo: ocorreu uma predicação por quantificação [...]; 
(iii) a transferência afetou a modalidade da classe-escopo: ocorreu uma predicação por modalização [...] (CASTILHO, 2014, p. 12-13).

Em conformidade ao estudioso, assumimos que o predicador pode tomar por sujeito tanto uma classe referencial quanto uma classe predicadora ou toda uma sentença, sendo que, nas três situações, à classe-sujeito é conferida uma contribuição semântica que não estava inscrita nas suas propriedades. Nesse contexto, o predicador "transfere a seu sujeito uma propriedade sua, que poderá ser (i) a emissão de um juízo sobre o valor de verdade da classe-sujeito, (ii) a alteração da extensão dos indivíduos designados pela classe-sujeito ou (iii) a alteração das propriedades intensionais da classe-sujeito (CASTILHO, 1994, p.81).

Assim, por meio da predicação, são adicionadas propriedades novas que não necessariamente alteram as propriedades preexistentes. Quanto aos diferentes tipos, Castilho (1994) afirma que a predicação manifesta-se por encadeamento, transferência ou cancelamento. No que tange especificamente a esta investigação, é oportuno que diferenciemos especialmente o encadeamento da transferência. Enquanto, no primeiro, tem-se uma predicação composicional, na qual são acrescentadas as propriedades que procedem do predicador às propriedades intensionais do item-sujeito, no segundo há uma predicação não composicional, pois o significado resultante não está nos sentidos dos itens relacionados. Como já assinalado na Introdução, hipotetizamos que a alteração de significado ocorrentes nas expressões em análise se dá via predicação por transferência, a qual envolve a transposição de traços de natureza figurativa.

\section{Expressões Formulaicas e Figuratividade}

De acordo com Amossy e Pierrot (1997), locuções, estereótipos e clichês fazem parte de um continuum de expressões cristalizadas, que se caracterizam pelo fato de que a cristalização atinge o enunciado todo. Nesse contexto, as expressões formulaicas consistem em "combinações de palavras associadas na mente de todos, freqüentemente repetidas em uma seqüência" (TANNEN; ÖZTEK, 1981, p. 37). O caráter formulaico dessas expressões tem garantia pela força da tradição cultural e pela remissão a pressupostos e 
representações, assim como a pré-construídos reconhecidos e compartilhados, assim como pelos falantes em situações socialmente situadas (MARCUSCHI, 2003).

Considerando as manifestações da predicação, a não composicionalidade gera as expressões formulaicas, segundo assinala Castilho (1994) citando Ilari (1992). Nesse caso, haveria maior comprometimento da intensão, já que o conjunto gerado é distante do sentido de cada palavra tomada individualmente. Isso fica evidente quando comparamos a expressão romance machadiano com a expressão elefante branco. No primeiro sintagma, temos uma relação de interseção entre as propriedades de romance e machadiano, em que não há o comprometimento da intensão de cada um dos vocábulos. Já, no segundo, conforme salienta Ilari, citado por Castilho (1994), no atual estágio da língua, o sentido que atribuiríamos a cada um dos constituintes do sintagma é irrecuperável, de modo que a intensão de cada uma das palavras não é preservada.

Explicitado isso, na predicação por transferência, de acordo com Castilho (1994, p. 83), "estariam alguns verbos auxiliares e as expressões idiomáticas ou formas cristalizadas, constituídas pela associação de classes tais como $\mathrm{V}+\mathrm{N}$ (por exemplo, em dar-se conta, ter tempo), $\mathrm{N}+$ Adj (como em elefante branco), etc." Acrescentamos a esse grupo a forma [SN + SP], em que SN é composto de especificador preenchido por pronome indefinido + substantivo em -ada: uma paulada, uma cacetada; e SP é formado por Preposição + SN: de presentes. Esse SP está encaixado no SN.

Com relação ainda aos formulaicos, importa-nos ressaltar que, frequentemente, há traços figurativos em sua constituição, o que acreditamos ocorrer com as expressões ora enfocadas. Visando a diferenciar sentido literal, de sentido não literal e de sentido figurado, Vilela (2005, p. 29) assevera:

o literal é o que aponta originariamente para o valor tido como primeiro (doce como me), o não literal é o sentido próximo desse primeiro valor (água doce, batata doce), em que não há afastamento entre fonte e destino (geralmente, é a área da metonímia ou nomeação) e o figurado começa na sinestesia (metaforicidade fraca: música doce, perfume doce, paisagem doce, clima doce) para acabar na metáfora propriamente dita (a área da metaforicidade forte: palavras doces, o sorriso doce de uma criança, o olhar doce de $x)$. 
Tal diferenciação não significa, no entanto, que essas formas do sentido sejam estanques e que uma preceda ou dê origem a outra, não sendo, pois, o sentido figurado de natureza secundária ou ornamental. Ao contrário, como assinalam Lakoff e Johnson (1980), a figuratividade é um processo sociocognitivo que conceptualiza e categoriza o mundo, uma vez que a própria mente está estruturada de maneira que o mapeamento do mundo só pode ser realizado através da corporização da atividade mental, fenômeno este que organiza a estrutura da linguagem. Assim, na língua, a figuratividade funciona da mesma forma que a não figuratividade, sendo a corporização do conhecimento feita por meio da experiência dos falantes.

Enquanto estratégia cognitiva na linguagem humana, a principal característica da figuratividade consiste no distanciamento entre o domínio fonte ou domínio do literal e o domínio ponto de chegada ou domínio figurado, havendo, dessa maneira, diferentes graus figurativos de acordo com os processos mentais envolvidos, entre os quais, no caso de itens lexicais, está a transferência de traços semânticos, fenômeno este de relevância para o trabalho em foco. Conforme atesta Vilela (2005), a depender do grau, a figuratividade revela-se na sinestesia, especialmente entre a classe circundante aos adjetivos, na metonímia, principalmente com relação aos nomes e à nomeação, e na metáfora, em todas as classes de palavras. Entendemos aqui a figuratividade como um processo complexo que, na medida em que é manifestada, no que se refere às expressões formulaicas em estudo, ocorre sob a forma de metaforicidade, concebida como um princípio cognitivo geral, no qual os mapeamentos metafóricos podem ser processados on-line (MIRANDA; MENDES, 2014).

\section{Aspectos Metodológicos}

Partindo de uma perspectiva semasiológica, em que se pretende a descrição dos diferentes sentidos de uma palavra ou expressão (SILVA, 2005), o fenômeno em análise foi investigado a partir de ocorrências identificadas em corpus especificamente formatado para as finalidades do presente estudo, de maneira que os procedimentos e técnicas empregados têm características predominantemente qualitativas, havendo quantificação apenas no que se refere à frequência absoluta e conforme tipificação das expressões, isto é, à frequência relativa. 
Sobre a constituição do corpus, cumpre destacar que ele é formado por expressões averiguadas e identificadas no portal Google. Em sua maioria, as expressões encontradas e identificadas estavam em fóruns de comentários, seções de reclamações e blogs. Há algumas ocorrências registadas em artigos de opinião e notícias, ambos publicados em revistas eletrônicas.

Inicialmente, os termos uma paulada de, uma porrada de, uma cacetada de, uma porretada de, uma pancada de e uma bordoada de foram digitados de forma isolada, entre aspas e sem a presença de nomes que os seguissem. Contudo, ao utilizar tal técnica, o portal buscador encontrou e apresentou elevado número de entradas em que as expressões designavam o ato de bater, em vez de a noção de quantidade/intensidade. Assim, após uma investigação prévia quanto à frequência de determinados nomes seguintes às expressões em foco, entre os quais estão coisas, críticas, dinheiro, gente, problemas, pessoas, novidades, tempo e jogos, passamos a, entre aspas e também isoladamente, digitar cada uma das expressões em análise juntamente a cada um dos termos referidos. Dessa maneira, este estudo não tem por pretensão ser exaustivo e representativo do fenômeno, mas explicitá-lo, descrevê-lo e procurar por suas motivações.

Em seguida à averiguação das expressões de interesse, suas ocorrências foram verificadas, compiladas, preservando-se o contexto em que foram produzidas, e quantificadas segundo sua prevalência geral e relativa. As análises das alterações semânticas ocorrentes nas expressões enfocadas foram desenvolvidas com base em categorias analíticas e explicativas tangentes à Semântica Cognitiva e à Semântica Diacrônica.

\section{Alterações Semânticas: de expressões designativas do ato de bater a expressões que indicam quantidade e intensidade}

Ao pesquisarmos as definições dos termos paulada, porrada, cacetada, porretada, pancada e bordoada, no dicionário, temos, em Bechara (2011):

PORRADA - sf. Tabu. 1 Pancada forte. 2 Grande número de. PAULADA - sf. 1. Golpe com pau. 2 Fig. Desgosto profundo. BORDOADA - sf. Pancada com bordão ou similar. 
CACETADA - sf. 1 Pancada com cacete; porretada. 2 Qualquer pancada forte. 3 Bras. Pop. Situação que aborrece; caceteação, maçada. 4 Bras. Pop. Grande quantidade; batelada.

PORRETADA - sf. Pancada desferida com porrete. 2 Golpe violento desferido com qualquer objeto.

PANCADA - sf. 1 Choque entre dois corpos; batida. 2 Ato de espancar. 3 Bras. Chuva forte; aguaceiro. 4. Pop. Quantidade considerável. 5 Bras. Pop. Que ou quem é amalucado.

Como pode ser observado, as seis palavras têm em comum o sentido de ato de bater, variando entre elas a forma ou o utensílio empregado na ação. Verificamos ainda nas definições dos vocábulos porrada, cacetada e pancada o sentido de quantidade, significado este que, em conjunto com o de intensidade, é verificado em um número elevado de ocorrências das expressões formulaicas em que estão contidas as seis palavras, cuja definição foi fornecida acima. Essas expressões são formadas ainda pelo especificador preenchido por pronome definido uma, pela preposição de e por um nome, ou seja, por $[\mathrm{SN}+\mathrm{SP}]$, conforme podemos verificar nos dados do corpus em análise:

1. Um torneio com uma pancada de pessoas, centenas e centenas, e na mesa final brilham oito profissionais do mais alto gabarito.

2. Uma porrada de gente morre de ataque cardíaco.

3. Joga há uma cacetada de tempo na Seleção Brasileira.

4. Guerrero recebe uma paulada de dinbeiro, pra ficar jogando futebol de Souza Caveirão.

5. Foi turnê, disco novo e mais uma porretada de coisas comemorativas.

6. Pelo que sei, O Templo da Perdição e A Última Cruzada receberam uma bordoada de críticas negativas na época de lançamento. 
Às expressões seguem-se nomes, que podem ser contáveis, como em pessoas, coisas e críticas, ou não contáveis, como em gente, tempo e dinheiro. Conforme mencionado na seção Aspectos Metodológicos, foram elencados substantivos para serem associados às expressões quando da realização das buscas. Além desses seis nomes, foram buscadas e encontradas ocorrências das expressões com problemas, novidades e jogos. No que se refere à frequência de cada expressão formulaica encontrada no corpus, que trataremos por frequência absoluta, segue a quantificação no quadro abaixo.

Quadro 1 - Frequência absoluta das expressões formulaicas encontradas no corpus

\begin{tabular}{|c|c|c|c|c|c|c|}
\hline Expressão & $\begin{array}{c}\text { Uma } \\
\text { pancada } \\
\text { de }\end{array}$ & $\begin{array}{c}\text { Uma } \\
\text { porrada } \\
\text { de }\end{array}$ & $\begin{array}{c}\text { Uma } \\
\text { cacetada } \\
\text { de }\end{array}$ & $\begin{array}{c}\text { Uma } \\
\text { paulada } \\
\text { de }\end{array}$ & $\begin{array}{c}\text { Uma } \\
\text { porretada } \\
\text { de }\end{array}$ & $\begin{array}{c}\text { Uma } \\
\text { bordoada } \\
\text { de }\end{array}$ \\
\hline $\begin{array}{l}\text { Número de } \\
\text { ocorrências }\end{array}$ & 785 & 1764 & 715 & 165 & 16 & 25 \\
\hline
\end{tabular}

Fonte: Elaborado pela autora.

Conforme representado no Quadro 1, a expressão formulaica uma porrada de é a que mais ocorre no corpus coletado, com mais que o dobro de ocorrências do que a expressão uma pancada de, a segunda mais frequente, seguida pela expressão uma cacetada de. Importante ressaltar que, entre as definições de dicionário analisadas, as palavras pancada, porrada e cacetada são aquelas em que são apontados os sentidos de quantidade. A expressão uma paulada de, quando comparada às três anteriores, possui frequência baixa, mas ainda alta, quando do cotejamento com as expressões uma bordoada de e uma porretada de, sendo esta a menos frequente.

No que se refere à frequência relativa, isto é, à frequência de ocorrência de cada expressão formulaica com cada substantivo buscado, temos as representações que se seguem. 
Para uma pancada de:

Quadro 2 - Frequência relativa das expressões formulaicas encontradas no corpus - uma pancada de

\begin{tabular}{|l|c|c|c|c|c|c|c|c|c|}
\hline Substantivos & Coisas & Críticas & Dinheiro & Gente & Problemas & Pessoas & Novidades & Tempo & Jogos \\
\hline $\begin{array}{l}\text { Número de } \\
\text { Ocorrências }\end{array}$ & 212 & 8 & 38 & 247 & 58 & 34 & 73 & 24 & 91 \\
\hline
\end{tabular}

Fonte: Elaborado pela autora.

Para uma porrada de:

Quadro 3 - Frequência relativa das expressões formulaicas encontradas no corpus - uma porrada de

\begin{tabular}{|l|c|c|c|c|c|c|c|c|c|}
\hline Substantivos & Coisas & Críticas & Dinheiro & Gente & Problemas & Pessoas & Novidades & Tempo & Jogos \\
\hline $\begin{array}{l}\text { Número de } \\
\text { Ocorrências }\end{array}$ & 329 & 45 & 212 & 369 & 157 & 118 & 124 & 255 & 155 \\
\hline
\end{tabular}

Fonte: Elaborado pela autora.

Para uma cacetada de:

Quadro 4 - Frequência relativa das expressões formulaicas encontradas no corpus - uma cacetada de

\begin{tabular}{|c|c|c|c|c|c|c|c|c|c|}
\hline Substantivos & Coisas & Críticas & Dinheiro & Gente & Problemas & Pessoas & Novidades & Tempo & Jogos \\
\hline $\begin{array}{l}\text { Número de } \\
\text { Ocorrências }\end{array}$ & 218 & 7 & 50 & 175 & 48 & 46 & 38 & 62 & 71 \\
\hline
\end{tabular}

Fonte: Elaborado pela autora.

Para uma paulada de:

Quadro 5 - Frequência relativa das expressões formulaicas encontradas no corpus - uma paulada de

\begin{tabular}{|c|c|c|c|c|c|c|c|c|c|}
\hline Substantivos & Coisas & Críticas & Dinheiro & Gente & Problemas & Pessoas & Novidades & Tempo & Jogos \\
\hline $\begin{array}{c}\text { Número de } \\
\text { Ocorrências }\end{array}$ & 51 & 6 & 24 & 47 & 0 & 5 & 0 & 15 & 17 \\
\hline
\end{tabular}

Fonte: Elaborado pela autora. 
Para uma porretada de:

Quadro 6 - Frequência relativa das expressões formulaicas encontradas no corpus - uma porretada de

\begin{tabular}{|l|c|c|c|c|c|c|c|c|c|}
\hline Substantivos & Coisas & Críticas & Dinheiro & Gente & Problemas & Pessoas & Novidades & Tempo & Jogos \\
\hline $\begin{array}{l}\text { Número de } \\
\text { Ocorrências }\end{array}$ & 6 & 2 & 0 & 7 & 0 & 0 & 0 & 0 & 1 \\
\hline
\end{tabular}

Fonte: Elaborado pela autora.

Para uma bordoada de:

Quadro 7 - Frequência relativa das expressões formulaicas encontradas no corpus - uma bordoada de

\begin{tabular}{|c|c|c|c|c|c|c|c|c|c|}
\hline Substantivos & Coisas & Críticas & Dinheiro & Gente & Problemas & Pessoas & Novidades & Tempo & Jogos \\
\hline $\begin{array}{c}\text { Número de } \\
\text { Ocorrências }\end{array}$ & 10 & 1 & 2 & 9 & 0 & 0 & 0 & 0 & 3 \\
\hline
\end{tabular}

Fonte: Elaborado pela autora.

Os substantivos coisas, críticas, gente e jogos aparecem acompanhando as seis expressões formulaicas. O substantivo dinheiro não acompanha a expressão uma porretada de; problemas, novidades e tempo não acompanham as expressões uma paulada de, uma porretada de e uma bordoada de; e pessoas não acompanha as expressões uma porretada de e uma bordoada de. Em termos de frequência, o substantivo coisas é o mais produtivo no acompanhamento das expressões formulaicas em análise, já que, além de estar presente junto a todas elas, quando comparado aos outros oito nomes, é aquele que mais ocorre em conjunto às expressões, exceto em uma porretada de, que, inclusive, é a menos frequente. É possível que a representatividade do nome coisas, em detrimento dos outros, frente às expressões, se deva à própria vagueza e indeterminação do seu significado, juntamente à informalidade do emprego desse substantivo. Com relação a todos os nomes, temos a hipótese de que a predominância dos substantivos não contáveis em conjunto à presença de um pronome indefinido como especificador do primeiro SN podem ser um dos fatores responsáveis pelo efeito de vagueza e indeterminação ocasionado pelas expressões. Entretanto, é necessária uma análise específica dessas conjecturas, o que não pretendemos, nem ainda podemos, neste estudo. 
Conforme explicitado na seção Aspectos Metodológicos, foi realizada uma investigação prévia quanto à frequência de determinados nomes seguintes às expressões em foco, de modo que, por razões de frequência, optamos pelos substantivos coisas, críticas, dinheiro, gente, problemas, pessoas, novidades, tempo e jogos. Cabe, contudo, destacar que outros nomes foram encontrados em ocorrência com as seis expressões formulaicas; são eles: contas, impostos, tramas, prêmios, movimentos, músicos, preço, anúncio, brasileiros, milhas, imagens, ideias, capas, material, aluno, detalhes, clones, trailers, opções, fornecedores, mãos, aparelhos, parágrafos, incisos, alineas, itens, máquinas, produtos, notícias, desenhos, truques, resenhas, países, prêmios, oportunidade, surfistas, fotos, trechos, redes, atividades, análises, pitacos, achismos, poderes, vez̧es, configurações, siglas, falhas, mensagens, irresponsáveis, especulações, juros, ofertas, corpos, soluções, aliados, inimigos, doces, bandas, e-mails, ações, qualidade e usuários.

Não temos por finalidade o desenvolvimento de análise exaustiva sobre a ocorrência e a frequência das expressões formulaicas em questão, contudo, vale a pena salientar que, como pode ser depreendido dos dados expostos, uma paulada de, uma porrada de, uma cacetada de, uma porretada de, uma pancada de e uma bordoada de designando quantidade e intensidade são bastante produtivas no português brasileiro.

Quanto especificamente aos processos que podem ter levado às alterações semânticas ocorrentes nas expressões designativas do ato de bater para um quantificador/intensificador, hipotetizamos ter havido o fenômeno de transferência de traços semânticos, gerado pela predicação de caráter não composicional, cujo operador consiste no sufixo -ada. Além disso, os traços semânticos de intensidade e força, constituintes dos itens lexicais paulada, porrada, cacetada, porretada, pancada e bordoada, foram reconfigurados de modo figurativo nas expressões criadas. Desse modo, as expressões formulaicas criadas predicam os termos que as seguem, transferindo a eles seus traços semânticos, tanto os figurativos já citados quanto os não figurativos contidos no sufixo -ada, a serem explicitados na sequência.

Em nossa hipótese, o sufixo -ada é o operador da predicação que movimenta os traços semânticos da expressão formulaica para os nomes que as seguem. Said Ali (1969) divide os sufixos em: i) os que funcionam ou originariamente funcionaram para formar nomes aumentativos e diminutivos e ii) aqueles que formam palavras novas e denotam outros conceitos diferentes, caso de -ada. No que se refere a -ada, o autor afirma que o sufixo forma substantivos com os possíveis significados: 
a) ferimento ou golpe; b) traço ou risco; c) medida ou quantidade que comporta o objeto representado pelo termo derivante; d) multidão; e) junto a nome de frutas e outros alimentos, denota certas bebidas, doces e preparados culinários; f) movimentos ou atos rápidos ou enérgicos; g) atos de duração prolongada (SAID ALI, 1969, p. 109).

Cunha e Cintra (2001, p. 94-95) classificam o sufixo -ada de acordo com o sentido que ele pode assumir: "a) multidão, coleção; b) porção contida num objeto; c) marca feita com um instrumento; d) ferimento ou golpe; e) produto alimentar, bebida; f) duração prolongada; g) ato ou movimento enérgico". Bechara (2004, p. 358-359) afirma que o sufixo -ada forma "nomes de ação ou resultado de ação, estado, qualidade, semelhança, composição, instrumento, lugar" e substantivos que designam "abundância, aglomeração, coleção". Conforme Correia (2004, p. 182-183), o sufixo -ada pode ter os sentidos de: "i. nomes de quantidade [...] i.a. coletivos [...] i.b. acrescentadores $[\ldots]$ ii. nomes de operações culinárias $[\ldots]$ nomes de conteúdos $[\ldots]$ iv. nomes de golpes [...] v. nomes de toques (sonoros) [...] vi. nomes de eventos $[\ldots]$ "..

Entre todos os autores acima referidos, há a asserção sobre o sufixo -ada como podendo denotar a noção de agrupamento, seja em multidão, na definição de Said Ali, multidão e coleção, na definição de Cunha e Cintra, abundância, aglomeração e coleção, na definição de Bechara, seja em nomes de quantidade e coletivos, na definição de Correia. Para nós, é justamente esse traço semântico do sufixo - ada que funciona como o operador da predicação por transferência nas expressões formulaicas, transpondo os sentidos de quantidade/intensidade aos nomes seguintes. Comparemos os termos abaixo para verificar isso.

\section{Pequenas Pedras}

8. Muitas pedras

9. Algumas pedras

10. Uma tonelada de pedras

11. Uma cacetada de pedras 
Em 7, o adjetivo pequenas predica sobre pedras, especificando sua dimensão. Identificamos aqui um mecanismo de predicação em que a transferência afetou a intensão da classe-escopo, ocorrendo uma predicação por qualificação. Em 8 e 9, os pronomes indefinidos muitas e algumas predicam sobre pedras, denotando sobre sua abundância e escassez, respectivamente. Em 10, a expressão uma tonelada de, composta por um artigo definido, um substantivo e uma preposição e que geralmente designa uma unidade de medida de massa, predica sobre pedras, especificando seu peso/quantidade. Já em 11, a expressão uma cacetada de, formada por um artigo definido, um substantivo e uma preposição, predica sobre pedras, denotando sua abundância. Observamos em 8, 9, 10 e 11 a existência de um mecanismo de predicação em que a transferência afetou a extensão da classe-escopo, ocorrendo uma predicação por quantificação.

Ainda que tonelada e cacetada sejam constituídas pelo sufixo -ada, aquela é, por definição, uma medida de peso/quantidade, enquanto esta consiste normalmente em uma expressão que designa o ato de bater. Assim, é o próprio termo tonelada que predica sobre pedras, ao passo que, em uma cacetada de pedras, o operador da predicação é o sufixo -ada, que transfere seu traço semântico de abundância para o substantivo. Nessa transferência, os traços semânticos de intensidade e força que constituem cacetada são selecionados e passam figurativamente a constar na noção de abundância configurada em uma cacetada de pedras. Processo semelhante ocorre com:

12. Me importo com uma porrada de pessoas e não sei se eu teria coragem de abraçar todo mundo.

13. O que fazemos é desenvolver o corpo através de movimentos funcionais, ou seja, que tenham uma função natural: agachar, arremessar, empurrar, puxar, girar, correr, saltar e mais uma pancada de movimentos que vão capacitar o seu corpo a realizar tarefas que até você mesmo duvidava.

14. Já que tinha uma cacetada de máquinas, fazendo uma cacetada de produtos, precisava vender.

15. Tudo dá margem a uma paulada de especulações, não é mesmo? 
16. Isso se eu responder, porque eu já recebo uma porretada de e-mails diariamente.

17. Sei que tem festa de aniversário de uma bordoada de gente.

Em todas essas ocorrências é patente que o significado das expressões formulaicas em análise não tem qualquer relação com a noção de um golpe de. Seus contextos sentenciais deixam claro que o significado pretendido pelos produtores das expressões diz respeito à especificação de que os referentes categorizados pelos nomes pessoas, em 12; movimentos, em 13; máquinas e produtos, em 14; especulações, em 15; e-mails, em 16; e gente, em 17, são considerados como sendo em abundância, havendo, portanto, traços de quantidade e intensidade. Se fôssemos hipotetizar a conceituação das expressões formulaicas em foco em uma classe gramatical conforme características e funcionalidades que possuem nas ocorrências encontradas no corpus, possivelmente, trataríamos delas, pelo menos em caráter provisório, como pronomes indefinidos, que se comportam tal qual muito, muita, muitos e muitas.

Diante do exposto, temos que a representação dos eventos contidos em pancada, porrada, cacetada, paulada, porretada e bordoada sofreu mudança semântica, de um sentido concreto para um sentido abstrato quando da presença dessas palavras nas expressões formulaicas geradas. Houve, assim, uma extensão do significado desses itens lexicais, que passaram, em termos gerais, de designativos do ato de bater para, em conjunto ao artigo uma e à preposição $d e$, a expressões que indicam quantidade, intensidade, abundância do nome que predicam.

\section{Conclusões}

Como destacado ao longo do trabalho, esta é uma investigação preliminar, sendo necessário: i) uma coleta maior de dados, de forma a aumentar a dimensão e consequente significância do corpus; ii) análises mais pormenorizadas e refinadas das ocorrências encontradas no corpus, de maneira a averiguar, por exemplo, a existência de traços semânticos que levem a alguma diferença de sentido entre as seis expressões formulaicas, e de possíveis padrões semânticos dos itens que seguem as expressões em análise; e iii) aprofundamento teórico-metodológico e analítico sobre aspectos relativos à predicação e, especialmente, à figuratividade, à qual, neste estudo preliminar, não foi dado relevo necessário. 
Quanto ao fenômeno investigado a partir das ocorrências encontradas no corpus e a partir do arcabouço teórico-metodológico empregado, podemos assumir, ainda que preliminarmente, que tanto a predicação, enquanto processo sintático-semântico, como a figuratividade são fatores responsáveis pelas alterações de sentido ocorrentes nas expressões designativas do ato de bater uma paulada de, uma porrada de, uma cacetada de, uma porretada de, uma pancada de e uma bordoada de, seguidas da preposição de, gerando expressões formulaicas que indicam quantidade, intensidade e abundância. Não é possível, porém, assumir que essas são as únicas motivações linguístico-cognitivas, sendo importantes investigações mais detalhadas, além da própria investigação etimológica, que será realizada em trabalhos posteriores.

No que se refere à predicação como um dos fenômenos envolvidos na mudança semântica investigada, especificamente a predicação por transferência, às expressões em foco são adicionadas propriedades novas, isto é, não presentes no uso de, por exemplo, uma cacetada, uma paulada, como expressões linguísticas designativas do ato de bater, cada qual se referindo ao emprego de instrumento para o golpe. Essas propriedades novas podem ter surgido em razão de uma função sintático-semântica que o uso do sufixo -ada, cuja denotação inclui as noções de agrupamento, abundância e aglomeração, passou a exercer nessas expressões. Dessa forma, tais expressões designativas do ato de bater passaram também a comportar sentidos de quantificação e de intensificação, sendo o contexto linguístico e o contexto situacional os fatores capazes de indicar os significados possíveis dessas expressões ao serem utilizadas. A partir das análises realizadas neste estudo, acreditamos ser justamente esse traço semântico do sufixo -ada o elemento que funciona como o operador da predicação por transferência nessas expressões formulaicas, transpondo os sentidos de quantidade/intensidade aos nomes seguintes.

Conforme exposto e discutido ao longo do artigo, as construções semânticas estudadas não ocorrem aleatoriamente. Embora algumas delas sejam bastante produtivas em Língua Portuguesa, parecem existir determinados contextos linguísticos que as favorecem, como antecederem substantivos não contáveis, entre os quais estão coisas, dinheiro e gente. Possivelmente, essa característica aliada à presença do pronome indefinido uma como especificador do primeiro $\mathrm{SN}$ consistem nos elementos 
responsáveis pelo efeito de vagueza e indeterminação ocasionado pelas expressões, que, mesmo indicando grande quantidade e intensidade, não são determinantes quanto a tais propriedades dos substantivos a que antecedem. Sobre essa hipótese, entretanto, é preciso ampliar o escopo da pesquisa, de modo a identificar também a prevalência de substantivos não contáveis frente aos contáveis nessas expressões, de forma a proceder a um levantamento exaustivo de suas ocorrências, atividade que está em sua fase inicial. Mesmo assim, o fato de os três substantivos mais frequentes nessas expressões serem do tipo não contável figura como um fato relevante para a hipótese aventada.

Partimos do pressuposto de que a configuração da cognição e, portanto, da linguagem humana, uma de suas formas de ser, é de caráter figurativo (LAKOFF; JOHNSON, 1980), propriedade esta que também estaria envolvida nos processos de mudança linguística, como o que tentamos apontar neste trabalho. Identificamos nos traços semânticos de intensidade e de força, presentes nos substantivos que constituem as expressões ora analisadas, o fator responsável, juntamente ao mecanismo predicativo explicitado, pela alteração de sentido criada. Não é somente a quantidade que está em jogo quando as expressões uma porrada de, uma pancada de, por exemplo, são usadas, mas também a intensidade, cujo valor semântico não advém do sufixo - ada, sendo, segundo hipotetizamos, provenientes de uma apropriação de traços dessas expressões quando elas designam o ato de bater, ou seja, dar uma porrada, levar uma pancada. Assim, trata-se de um processo metafórico, em que traços de um domínio são transportados para o outro, cujo resultado é a origem de expressões que além de metafóricas são é idiomáticas e formulaicas. Fornece sustento a essa hipótese o fato de serem expressões que designam o ato de bater e não quaisquer outras as expressões que passaram a atuar como quantificadores/intensificadores dos nomes que seguem a elas.

Esta pesquisa está sendo ampliada e aprofundada, haja vista a necessidade de entender o fenômeno de modo mais refinado. Cumpre destacar que estudos alicerçados em outras perspectivas linguísticas seriam de grande valia para auxiliar na compreensão das alterações semânticas ocorrentes em expressões designativas do ato de bater, originando expressões que indicam quantidade e intensidade. 


\section{Referências}

ALENCAR, R. B. E ai? Uma proposta descritiva das expressões formulaicas para português L2 para estrangeiros. 2004. Tese (Doutorado em Letras) - Pontifícia Universidade Católica do Rio de Janeiro, Rio de Janeiro.

AMOSSY, R.; PIERROT, A. H. Stéréotypes et clichés: langue, discours, société. Paris: Nathan Université, 1997.

BECHARA, E. Moderna gramática portuguesa. 37. ed. rev. e ampl. Rio de Janeiro: Nova Fronteira, 2004.

BECHARA, E. Dicionário da Lingua Portuguesa Evanildo Bechara. Rio de Janeiro: Nova Fronteira, 2011.

BRÉAL, M. Éssai de sémantique. Paris: Hachette, 1911.

CASTILHO, A. T. Um ponto de vista funcional sobre predicação. ALFA, v. 38, p. 75-95, 1994.

CASTILHO, A. T. Proposta funcionalista de mudança lingüística: lexicalização, semanticização, discursivização e gramatizalização das preposições do eixo transversal no Português Brasileiro. 2003. Disponível em: <http://bit.ly/2BUsH99>.

CASTILHO, A. T. O que é a Semântica? 2014. Disponível em: $<$ http://bit.ly/2jOWMQK>.

CAZELATO, S. E. de O. A ocorrência espontânea de expressões formulaicas no contexto patológico: estudo da competência pragmáticodiscursiva. Estudos Lingüisticos, v. 35, p. 1786-1792, 2006.

CORREIA, M. Denominação e construção de palavras: o caso dos nomes de qualidade em português. Lisboa: Colibri, 2004.

CUNHA, C.; CINTRA, L. Nova gramática do português contemporâneo. 3. ed. Rio de Janeiro: Nova Fronteira, 2001. 
LAKOFF, G.; JOHNSON, M. Metaphors we live by. Chicago: University of Chicago Press, 1980.

MARCUSCHI, L. A. Do código para a cognição: o processo referencial como atividade cognitiva. Veredas, v. 10, p. 43-62, 2003.

MARTELOTTA, M. E. Mudança linguística. Uma abordagem baseada no uso. São Paulo: Cortez, 2011.

MIRANDA, M. A.; MENDES; P. H. A. A emergência de metáforas multimodais: análise da metaforização e da compressão no debate político-eleitoral. SCRIPTA, Belo Horizonte, v. 18, n. 34, p. 237-256, jul./dez. 2014.

PEZATTI, E. G. O Funcionalismo em linguística. In: MUSSALIM, F.; BENTES, A. C. (Org.). Introdução à linguística: fundamentos epistemológicos. v. 3. 5. ed. São Paulo: Cortez, 2011.

SAID ALI, M. Gramática secundária da língua portuguesa. São Paulo: Melhoramentos, 1969.

SAUSSURE, F. Curso de lingüistica geral. 6. ed. São Paulo: Cultrix, 1974.

SILVA, A. S. Palavras e conceitos no tempo: para uma onomasiologia diacrónica e cognitiva do Português. In: FACULDADE DE LETRAS DA UNIVERSIDADE DO PORTO. Secção de Linguística. Departamento de Estudos Portugueses e de Estudos Românicos (Org.). Estudos em homenagem ao Professor Doutor Mário Vilela. Porto: Faculdade de Letras da Universidade do Porto, 2005.

SILVA, A. S.; BATORÉO, H. J. Gramática cognitiva: estruturação conceptual, arquitectura e aplicações. In: BRITO, A. M. (Org.). Gramática: história, teorias, aplicações. Porto: Faculdade de Letras da Universidade do Porto, 2010.

TANNEN, D.; ÖZTEK, P. Health to our mouths: Formulaic expressions in Turkish and Greek. In: COULMAS, F. (Ed.). Conversational Routine: explorations in standardized communication situations and prepatterned speech. v. 2. Paris; Nova Iorque: Mouton, 1981. p. 37-53 
ULLMANN, S. Semântica: uma introdução à ciência do significado. Tradução J. A. Osório Mateus. Lisboa: Fundação Calouste Gulbenkian, 1964.

VILELA, M. A. Q. Três estratégias cognitivas da figuratividade na língua: sinestesia, metáfora e metonímia. In: FACULDADE DE LETRAS DA UNIVERSIDADE DO PORTO. Secção de Linguística. Departamento de Estudos Portugueses e de Estudos Românicos (Org.). Estudos em homenagem ao Professor Doutor Mário Vilela. Porto: Faculdade de Letras da Universidade do Porto, 2005.

Recebido em: 15/04/2016

Aceito em: 16/08/2016 